\title{
Investigation and Analysis on the Construction of MOOC and the Utilization of Curriculum in Colleges and Universities in China
}

\author{
Xiuli $\mathrm{Li}^{*}$ \\ Jilin Business and Technology College \\ *Corresponding author: Xiuli Li, librarian,15904429276,lixiulibb@126.com
}

\begin{abstract}
This paper mainly analyzes to opened courses and resource utilization of teachers in our country on the five main platforms which is Chinese University MOOC, xuetangx, Coursera, cnmoocand Guokr, to understand the current situation and attitude of the MOOC construction and provide a new pattern for the innovation and development of University library.
\end{abstract}

Key words: $M O O C$; university library; innovative service

In 2012, MOOC as "digital tsunami" swept the world, opened the door to the Ivy League university. Peking University, Fudan University, Chinese University Hong Kong, National Taiwan University and other 6 schools have joined the Coursera platform in 2013. At present, 15.5 million from 162 countries students learning the EDX first course "Massachusetts circuit and Electronics", Professor Agarwal Anant, chairman of the EDX, told an interview that the Chinese education is going through the historical moment of "moving the book" to "moving in the classroom". At the same time, China also launched a local MOOC- MOOC in China of Netease and the higher education community to jointly launched the online education platform, She undertook the Ministry of education national boutique open curriculum task, to the public to provide Chinese famous universities MOOC curriculum; Followed by Tsinghua University, school online, is currently China's largest MOOC platform, and "CNMOOC" is the independent research and development of China's high level MOOC alliance platform in Shanghai Jiao Tong University; the "MOOC institute" under the Guokr is the largest open online course forum, which collected all the courses of Coursera, Udacity, EDX. This paper investigates five platform of China University MOOC, xuetangx, Coursera, CNMOOC, and Guokr, understands the situation and attitude of the teachers' MOOC construction and curriculum utilization in our country, so as to promote the sustainable development of MOOC.

\section{Questionnaire design content and related information}

The questionnaire for descriptive statistics, xuetangx, Coursera, five platform 150 teachers and 50 students by e-mail one to one payment, the issued 200 questionnaires, recovery of 190 copies, effective questionnaire 190. The object of investigation is the platform teachers and 
students who received a certificate of completion. As of May 31, 2016, MOOC enrollment of nearly about 600000 people in China's mainland area, on-line courses which is haved for construction of the teachers in china is a total of 710 courses. Survey content: For teaching teachers, there are basic information, construction motivation, time investment and so on. For the course of the use of resources, it has the number of courses, the use of learning resources, content difficulty, credit courses, etc..

2 Investigation and analysis of the construction of MOOC about teachers of the online learning platform in our country

\subsection{The investigation and analysis of the number of courses, concern, the user to obtain a certificate and other aspects in online learning platform}

The author uses the method of sorting, investigation and analysis to analyze the basic information of the course of Chinese University $\mathrm{MOOC}^{1}$, xuetangx ${ }^{2}, \mathrm{CNMOOC}^{3}$, Coursera $^{4}$ four platforms. The results show that the largest number of courses on Coursera, the highest degree of concern, the highest user certificate, MOOC what Chinese teachers constructed is mainly distributed in the Chinese University MOOC, while the curriculum is the highest average xuetangx. Throughout the visible, most of the teachers in Colleges and universities have accepted and opened MOOC, especially in the international Coursera platform there are 107, which shows that the information literacy of teachers and students in our country has been greatly improved. See Table 1 for details.

Table 1 Basic information table on online learning platform

\begin{tabular}{|l|l|l|l|l|l|}
\hline Online learning platform & All courses & $\begin{array}{l}\text { Courses offered by } \\
\text { teachers in our country }\end{array}$ & $\begin{array}{l}\text { Course } \\
\text { attention }\end{array}$ & $\begin{array}{l}\text { User } \\
\text { certificate }\end{array}$ & $\begin{array}{l}\text { Course } \\
\text { average }\end{array}$ \\
\hline xuetangx & 288 & 216 & $209 \mathrm{~K}$ & $1 \mathrm{~K}$ & 9.4 \\
\hline $\begin{array}{l}\text { Chinese University } \\
\text { MOOC, }\end{array}$ & 341 & 332 & $167 \mathrm{~K}$ & 882 & 9.1 \\
\hline CNMOOC & 62 & 55 & $35 \mathrm{~K}$ & 182 & 8.8 \\
\hline Coursera & 1797 & 107 & $1296 \mathrm{~K}$ & $6 \mathrm{~K}$ & 9.2 \\
\hline
\end{tabular}

\subsection{0 course distribution}

Survey results show that 01 philosophy 4\%; 02 economics 2\%; 03 law 3\%; 04 education 4\%; 05 literature 7\%; 06 history 4\%. 07 science 27\%; 08 engineering 30\%; 10 medicine 11\%; The maximum percentage of engineering is $30 \%$, followed by science $27 \%$; the least subject is economics $2 \% .07,08,10$ are collectively referred to as the natural sciences, the percentage is $68 \%$; the social science is $32 \%$;Conclusion: the basic course of the university is 106 , accounting for $15 \%$; the social course is 127 , accounting for $18 \%$; university professional course 475 , accounting for $67 \%$. 


\subsection{The distribution of teachers, teaching}

Survey results show that the various platforms of the MOOC teachers are the backbone of the teaching of each school, has a more mature teaching and scientific research among them, the title of senior teachers percentage is $58 \%$; accounted for the ratio is the highest, followed by Vice senior titles, the percentage was 34\%; intermediate accounted for only $8 \%$; teaching experience for more than 21 years accounted for the highest proportion of $41 \%$; visible MOOC teacher's own condition was able to guarantee the quality of teaching. See Figure 1 for details.

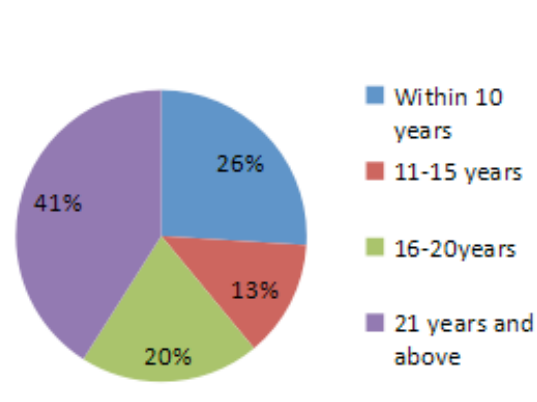

Figure 1 Teaching age

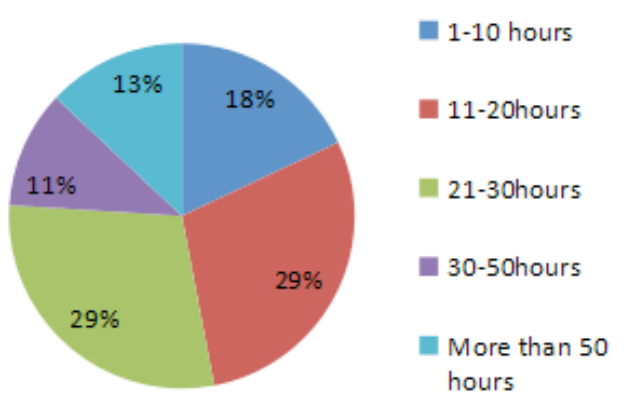

Figure 2 Mooc construction time investment

\subsection{MOOC construction time investment}

Survey results show that the production of a lecture (that is, a week) the average cost of the course is about 23 hours; Spend most of the time is 11-20 hours and 21-30 hours; while the traditional course takes about 2-5 hours will be able to complete a week of classes, visible, the time required for the production of MOOC is 2-4 times the traditional courses. See Figure 2 for details.

\subsection{The motivation of college teachers' construction of MOOC}

Survey results show that hope my class can help more people need to be the largest proportion of $91 \%$, followed by the hope that the transformation of school teaching, the proportion was $70 \%$; Through building MOOC, combing curriculum resources of $64 \%$; tripartite accounted for the largest proportion, focused on teaching itself, on the one hand may is out of social responsibility, to help more people, on the other hand is hope the curriculum or teaching can be improved. In addition, there are $17 \%$ orders from the superior, it can be seen that the early opening of the majority of teachers in the course of MOOC is voluntary.

\subsection{Credit course}

This is mainly about the MOOC whether as a credit course to do the survey. According to the results of the survey, from 14 universities 21\% teacher MOOC is in the school as a credit use, that is, students can get credit, this school is a comprehensive university. For example: Wuhan University course $\mathrm{Mu}$ as a credit course use; Whether their courses as a credit course is used 
by other schools $25 \%$ of the teachers said their courses in other schools as the use of credit, these courses are more basic or general education courses, there are 12 courses from the University of eastern and western curriculum sharing alliance. For example: Zhongnan University of Economics and Law, the official will be 8 courses of MOOC included in the list of undergraduate elective course, After graduation, the students can obtain the corresponding general elective credits. This policy is a quick get students welcome, more than 5000 undergraduate students, there are 1400 people enrolled in the MOOC $^{5}$,whether teachers' understanding of their courses is as a credit course, for more details, see the following two charts.

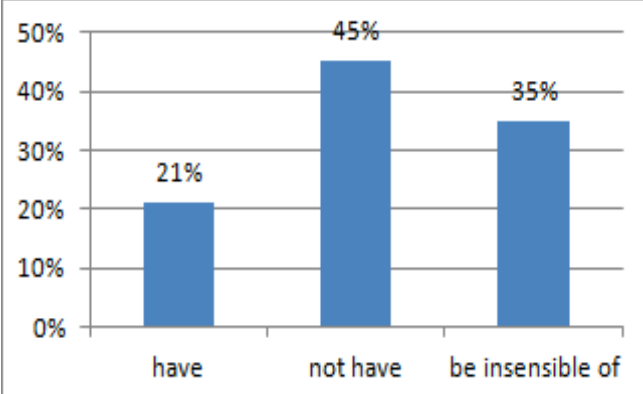

Figure 3 This school ${ }^{6}$

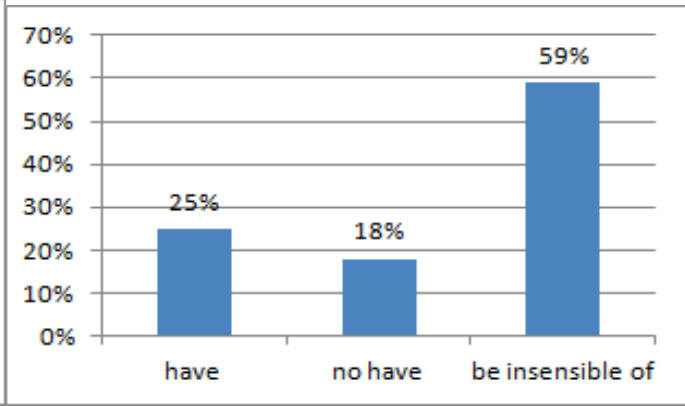

Figure 4 Other school ${ }^{5}$

\section{Investigation and analysis on the utilization of $M O O C$ in online learning platform}

\subsection{The number of classes}

At present, it has formed a number of MOOC learning community in the country. Among them, the biggest learning community for fruit shell network ${ }^{8}$. Most students, compared with representative. Survey results show that MOOC students are mainly college students and employees in the two part, the proportion of students accounted for more than half, Their elective courses are mainly in the nature of literature, science and economics, the prime minister to the humanities, relatively speaking, the choice of natural science students.

\subsection{The use of learning resources}

The survey found that the MOOC students to elective courses courseware, teaching materials and teachers cited references using rate is higher, accounted for more than $55 \%$. Secondly, to study notes, compared to 43 percent, at least for review, the ratio is $16 \%$.Students get more than $83 \%$ of the resources of the channel for the MOOC platform, followed by various types of search engines and mutual aid platform, the proportion of $55 \%$ and $53 \%$, the utilization rate of the library is the lowest, only $11 \%$. The biggest discovery of this survey is to obtain and share the most important way of MOOC resources for the MOOC discussion area, WeChat public number, QQ group, etc..For more details, see the following two charts. 


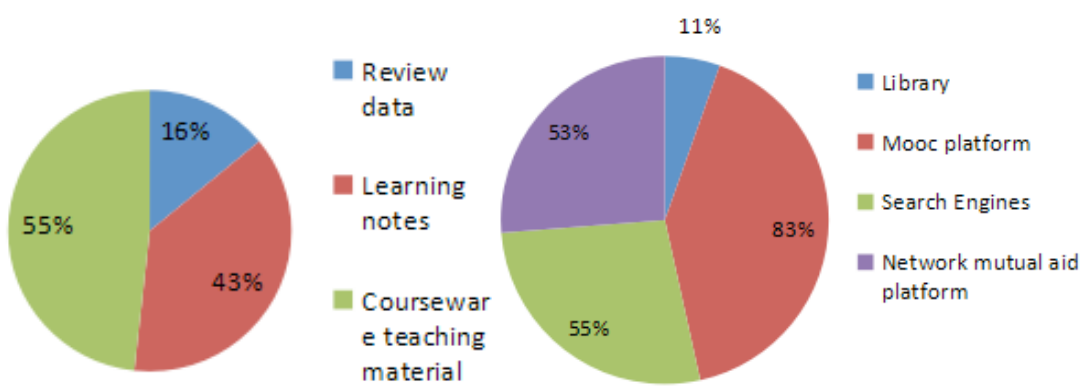

Figure 5 Learning resource utilization ${ }^{8} \quad$ Figure6 Resource acquisition channel $^{8}$

\subsection{Content difficulty}

Research shows that nearly half of the students believe that teaching is difficult and graduation requirements lower than the traditional classroom; Specific as: $20 \%$ think are the same, but MOOC practice more; $10 \%$ think the teaching content to increase some of the school does not speak the humanities knowledge, difficulty and graduation requirements unchanged; $8 \%$ of the students think that teaching content, higher graduation requirements, $7 \%$ thinks it is a completely different two courses, thus, the students of the cognitive impression of the class is better than the traditional classroom.

\subsection{Needs of the library}

Survey found that ninety percent of respondents believe that the need for library services, of which seventy percent think very much", Survey found that ninety percent of respondents believe that the need for library services, of which seventy percent think "very much", especially in the MOOC learning places, information literacy, courseware download, subject navigation, textbooks and reference books, etc. and for information consulting, document delivery and other basic services demand is low. It can be seen that the MOOC of the learning staff in-depth study and self - learning is generally higher, At the same time, in the information age, the digital age, the library service is also essential, compared to the traditional service, may be in the service content, mode, some of the changes, the constant is the theme of the eternal service of the library.

Through a series of MOOC teachers' attitudes towards the construction of MOOC, the social science teachers' enthusiasm for building MOOC was slightly higher than that of natural science teachers; Teacher production of MOOC workload is very large, through the investigation of the above that, the production of a lecture time is 2-4 times the traditional curriculum time, more than half of the teachers believe that the production of MOOC interfere with their normal teaching and research. Therefore, the sustainable development of MOOC, the university can be based on the relevant policies issued by the Ministry of education, the actual situation of their own schools, the actual workload of teachers to operate MOOC. Tsinghua University, for example, has issued relevant support policies, in January 2014, issued a number of opinions on strengthening the work of online education in the Tsinghua 
University, the notice, made it clear that first semester during the work to give the corresponding traditional courses 3 times; ${ }^{1}$ The teacher intercollegiate cooperation or cross transnational cooperation will more strongly. So to encourage exchange and cooperation between universities and international universities and to meet the needs of teachers' teaching and help to the improvement of MOOC quality.

Through a series of MOOC students learning attitude survey that, compared to the traditional courses, students prefer online courses, where they are interested in the release of their hobbies, you can choose according to their favorite courses, learning time and the way more flexible; Compared with the natural science curriculum, students prefer the course of social science, at the same time, the service of the library also put forward higher requirements.

\section{Conclusion}

MOOC as the representative of the online education as a digital product of the outbreak and the speed of the fast, all kinds of schools at all levels should take the initiative to take measures to strengthen the teaching reform, Through the reform of teaching methods and methods to promote the construction of curriculum, The construction and education of MOOC, the teaching concept has become a suitable for China's national conditions and has the characteristics of modern education mode, and effectively improve the quality of education. his needs to clarify the internal mechanism, curriculum construction and the use of the formation of effective closed loop, resulting in a positive feedback, to ensure sustainable development. At the same time, the recognition of credit, the result is the key factor in the sustainable development of MOOC.

\section{Acknowledgements}

This paper is one of the research results of "Study on the transformation of service mode of University Library under the environment of MOOC" which is Jilin Province in 2016 "13th Five-Year" key scientific research projects(Project No.: 110th, 2016); This paper is also one of the research results of "Research on the construction of Changbai Mountain tourism resources information database under the concept of MOOC" which is Jilin business school in 2016 the humanities and Social Sciences project(Project No.: 001th, 2016).

\section{References}

1. http://www.icourse163.org/(31.5.2016.)

2. http://www.xuetangx.com/(31.5.2016.)

3. http://www.cnmooc.org/portal/frontCourseIndex/course.mooc(3.5.2016.)

4. http://mooc.guokr.com/platform/Coursera/(31.5.2016.)

5. http://news.ifeng.com/a/20150402/43466010_0.shtml.(2.4.2016.)

6. http://www.icourse163.org/course/WHU-29001\#/info(2.4.2016.)

8. http://mooc.guokr.com/(31.5.2016.) 